\title{
Sinopse do gênero Andropogon L. (Poaceae -Andropogoneae) no Brasil ${ }^{1}$
}

\author{
ANA ZANIN ${ }^{2,4}$ e HILDA MARIA LONGHI-WAGNER ${ }^{3}$
}

(recebido: 31 de março de 2005; aceito: 1 de junho de 2006)

\begin{abstract}
Synopsis of the genus Andropogon L. (Poaceae - Andropogoneae) in Brazil). A survey of the genus Andropogon for Brazil confirmed the occurrence of 28 species, one of them introduced from Africa, A. gayanus Kunth. A synopsis of the species, including a key for their identification, illustrations as well as data on their geographic distribution are presented.
\end{abstract}

Key words - Brazil, distribution, grasses, taxonomy

RESUMO - (Sinopse do gênero Andropogon L. (Poaceae - Andropogoneae) no Brasil). A revisão do gênero Andropogon para o Brasil revelou a ocorrência de 28 espécies, uma das quais introduzida da África para cultivo, A gayanus Kunth. Neste trabalho é apresentada uma chave para identificação das espécies, ilustrações de caracteres diagnósticos e dados sobre a distribuição geográfica das mesmas.

Palavras-chave - Brasil, distribuição, Gramineae, taxonomia

\section{Introdução}

O gênero Andropogon L. é um dos mais representativos da tribo Andropogoneae. Possui cerca de 100 espécies, distribuídas especialmente nos trópicos, com centros de diversidade específica na África e América Tropical (Clayton \& Renvoize 1982). Apresenta quatro seções de acordo com Stapf (1917-1919) e Clayton \& Renvoize (1986), Andropogon, Piestium, Notosolen e Leptopogon, sendo a maior parte das espécies americanas pertencentes à última seção.

No continente americano, o gênero está mais bem representado na América do Sul, com o maior número de espécies ocorrendo no Brasil. A diversidade específica mais elevada ocorre nas formações de cerrado e campos rupestres das Regiões Sudeste e Centro-Oeste.

As espécies são, em sua maioria, perenes e de hábito cespitoso, muitas delas destacando-se a campo por apresentar inflorescências plumosas. Ocorrem em campos úmidos ou secos, em áreas alteradas, como margens de estradas e clareiras, ou em locais em estágio inicial de sucessão.

1. Parte da tese de doutorado da primeira autora, Programa de Pós-Graduação em Botânica da Universidade de São Paulo, Instituto de Biociências, São Paulo.

2. Universidade Federal de Santa Catarina, Campus Universitário, Departamento de Botânica, Trindade, 88040-900 Florianópolis, SC, Brasil.

3. Universidade Federal do Rio Grande do Sul, Departamento de Botânica, Avenida Bento Gonçalves 9500, prédio 43323, 91501-970 Porto Alegre, RS, Brasil.

4. Autor para correspondência: anazanin@ccb.ufsc.br
No Brasil, destacam-se os trabalhos de Nees (1829) e Hackel (1883), os quais apresentam descrições originais e detalhadas para algumas espécies, porém sem chaves de identificação. O conceito de Andropogon aceito por Hackel (1883) inclui vários subgêneros reconhecidos hoje como gêneros. Mais recentemente, foram desenvolvidos alguns trabalhos para floras regionais com inclusão de chave e/ou descrições e ilustrações. Destacam-se Hervé \& Valls (1980), para o Rio Grande do Sul, Smith et al. (1982), para Santa Catarina, Renvoize $(1984,1988)$ para a Bahia e Paraná, respectivamente, e Zanin (2001b), para São Paulo.

Este trabalho é parte da revisão do gênero para o Brasil (Zanin 2001a), baseada na análise da morfologia externa, anatomia da lâmina foliar e da superfície de fruto em microscopia eletrônica de varredura. No presente trabalho são incluídos apenas os dados de morfologia externa, tendo, como objetivos, fornecer meios para a identificação das espécies confirmadas e contribuir para o conhecimento da flora agrostológica brasileira.

\section{Material e métodos}

O trabalho foi baseado na análise da morfologia externa, utilizando materiais depositados em herbários, bem como materiais coletados em viagens realizadas entre janeiro de 1996 e junho de 1999, nas Regiões Sul, Sudeste, Centro-Oeste e Nordeste do Brasil. Os seguintes herbários nacionais e internacionais foram revisados, incluindo coleções históricas e exemplares-tipo, cibacopies e fotocópias da maioria dos táxons estudados: ALCB, ASE, B, BHCB, BHMH, BM, BR, C, CEN, CEPEC, CESJ, CH, CGMS, CPAP, CTES, CVRD, ESA, ESAL, F, FI, FLOR, FUEL, G, GUA, HB, HRB, HRCB, HUCS, 
HUEFS, HURG, IAC, IAN, IBGE, ICN, INPA, IPA, JPB, K, L, LINN, M, MBM, MBML, MG, MO, NY, P, PEL, PEUFR, PMSP, PR, PRE, QCA, R, RB, SMDB, S, SP, SPF, SPSF, TEPB, UB, UEC, UFMT, UPCB, US, VIC, VIES, W (siglas segundo The New York Botanical Garden 2005). Além destes, foram revisados o Herbário da Empresa Brasileira de Pesquisa Agropecuária de Bagé, Rio Grande do Sul (CNPO), Herbário da Empresa Brasileira de Pesquisa Agropecuária de Planaltina, Distrito Federal, (CPAC), Herbário “Goro Hashimoto”, de São Paulo (HGB), e Herbário da Universidade Estadual de Ponta Grossa, Paraná (HUEPG), não registrados oficialmente.

Cita-se apenas um exemplar selecionado de cada espécie, como testemunho. Uma lista completa do material examinado, bem como uma lista de exsicatas, por coletor, encontra-se à disposição de leitores interessados, com a primeira autora.

\section{Resultados}

Andropogon L., Sp. pl. 1:1045. 1753.

Diectomis Kunth, Mém. Mus. Hist. Nat. Paris, 2. 69:1815, nom. cons., non P. Beauv. 1812.

Hypogynium Nees, Agrostologia brasiliensis, in Mart., Fl. bras. enum. pl. 2(1):364. 1829.

Plantas perenes ou anuais, geralmente cespitosas, às vezes, rizomatosas. Colmos simples ou ramificados, 20-300 cm de altura. Inovação intravaginal. Prefoliação conduplicada ou convoluta. Lígula membranosa, membranoso-ciliolada, membranoso-ciliada ou ciliolada; lâminas lineares ou linear-lanceoladas, de base reta ou atenuada, ou lanceoladas de base cordada ou subcordada, geralmente planas, menos comumente cilíndricas e com a face adaxial reduzida a um pequeno sulco, às vezes crispadas, ápice acuminado, agudo ou obtuso. Inflorescências pouco ou muito ramificadas na metade superior dos colmos floríferos, terminais e axilares, às vezes só terminais; cada ramificação termina em uma unidade de inflorescência formada por uma folha modificada, geralmente reduzida ou quase reduzida à bainha foliar, denominada espatéola, e por dois ou mais ramos floríferos (racemos, segundo alguns autores) que portam as espiguetas, menos freqüentemente apenas um ramo florífero por espatéola. Espiguetas aos pares sobre o nó da ráquis, uma séssil ou subséssil e outra pedicelada, as sésseis do ápice de cada ramo florífero acompanhada de duas pediceladas, cada espigueta com dois antécios. Ráquis desarticulando-se em cada nó, de modo que a espigueta séssil, o entrenó da ráquis e a espigueta pedicelada geralmente caem juntos, formando uma unidade de dispersão. Entrenó da ráquis e pedicelo lineares, clavados ou subclavados, variadamente plumosos ou escabros, ápice inteiro, lobado ou ondulado. Espiguetas sésseis dorsal ou lateralmente comprimidas, aristadas ou múticas, calo obtuso, piloso ou glabro; glumas subiguais, ocultando completamente os antécios; gluma inferior bicarenada, cartácea ou subcoriácea, plana ou côncava, com ou sem um sulco longitudinal central, com ou sem nervuras entre as carenas; gluma superior unicarenada; antécio inferior neutro; lema inferior bicarenado, hialino ou vináceo; pálea inferior ausente; antécio superior com flor bissexuada, ou pistilada por redução dos estames a estaminódios; lema superior hialino ou palhete-hialino, inteiro, bidentado ou bífido em diferentes graus, no máximo até a metade, aristado ou mútico; pálea superior hialina; lodículas 2; estames 3 ou 1 , às vezes $1-3$ estaminódios. Fruto cariopse. Espiguetas pediceladas desenvolvidas ou com diferentes graus de redução e neutras, raramente suprimidas; quando desenvolvidas são múticas, raramente aristadas, comprimidas ou não dorsalmente; glumas subiguais, ocultando os antécios; gluma inferior simétrica, raramente assimétrica (A. fastigiatus); antécio inferior neutro; lema inferior hialino; pálea inferior ausente; antécio superior com flor estaminada ou, menos comumente, bissexuada; lema superior hialino; pálea superior presente, raramente ausente (A. virgatus), hialina; lodículas 2; estames 3.

\section{Chave para as espécies de Andropogon L. ocorrentes no Brasil}

1. Inflorescência com um ramo florífero por espatéola

2. Espiguetas sésseis múticas

3. Espiguetas sésseis com flor bissexuada. Entrenós da ráquis e pedicelos pilosos, tricomas mais curtos ou atingindo até 1,5 vezes o comprimento da espigueta séssil .... A. crucianus

3. Espiguetas sésseis com flor pistilada. Entrenós da ráquis e pedicelos escabros A. virgatus

2. Espiguetas sésseis aristadas

4. Gluma inferior da espigueta pedicelada assimétrica, aristada. Entrenós da ráquis e pedicelos clavados A. fastigiatus

4. Gluma inferior da espigueta pedicelada simétrica, mútica. Entrenós da ráquis e pedicelos lineares ou subclavados 
5. Gluma inferior da espigueta séssil com nervuras entre as carenas. Plantas até $110 \mathrm{~cm}$ de altura. Espiguetas pediceladas sempre estaminadas ou sempre neutras, ou neutras e estaminadas na mesma planta. Anteras das espiguetas sésseis e pediceladas subiguais no comprimento, atingindo 1,2-1,9 mm compr.

6. Espiguetas pediceladas 1,5-2,2 mm compr., neutras. Entrenós da ráquis e pedicelos com tricomas mais curtos que a espigueta séssil. Lema inferior da espigueta séssil 3,4-4 mm compr.

A. palustris

6. Espiguetas pediceladas 3,5-7,2 mm compr., estaminadas, ou estaminadas e neutras ocorrendo ao longo e no ápice dos ramos floríferos, raramente só neutras na mesma planta. Entrenós da ráquis e pedicelos com tricomas do mesmo comprimento ou até duas vezes o comprimento da espigueta séssil, menos comumente mais curtos. Lema inferior da espigueta séssil 4-6 mm compr.

A. ingratus

5. Gluma inferior da espigueta séssil sem nervuras entre as carenas. Plantas de $170-250 \mathrm{~cm}$ de altura. Espiguetas pediceladas sempre estaminadas, raramente algumas espiguetas pediceladas neutras na mesma planta. Anteras das espiguetas sésseis e pediceladas desiguais no comprimento, atingindo 0,6-1 mm compr. nas espiguetas sésseis e 2-2,5 mm nas pediceladas A. monocladus

1. Inflorescência com dois ou mais ramos floríferos por espatéola

7. Lâminas foliares lanceoladas, crispadas quando envelhecidas. Rizomas bem desenvolvidos

A. crispifolius

7. Lâminas foliares lineares ou linear-lanceoladas, nunca crispadas. Rizomas ausentes ou pouco desenvolvidos

8. Gluma inferior da espigueta pedicelada aristada, arista (1,5-)4,2-9 mm compr.

9. Espiguetas sésseis 7,2-8,2 mm compr., gluma inferior elíptico-lanceolada, plana, com sulco mediano e com nervuras entre as carenas. Gluma inferior da espigueta pedicelada com 20 a mais nervuras

A. gayanus

9. Espiguetas sésseis 4,2-5,5(-7) mm compr., gluma inferior linear, profundamente côncava, sem sulco e sem nervuras entre as carenas. Gluma inferior da espigueta pedicelada 7nervada

A. angustatus

8. Gluma inferior da espigueta pedicelada mútica

10. Lâminas foliares linear-lanceoladas, ápice longamente acuminado. Entrenós da ráquis clavados, às vezes subclavados na mesma planta

11. Espiguetas pediceladas 2-4 mm compr., gluma inferior 7-11-nervada. Espiguetas sésseis com arista de 8-15 mm compr.....

A. indetonsus

11. Espiguetas pediceladas 7,1-10 mm compr., gluma inferior com 14 ou mais nervuras.

Espiguetas sésseis com arista de 18-22 mm compr.

A. pohlianus

10. Lâminas foliares lineares, de ápice apiculado ou variadamente agudo a obtuso. Entrenós da ráquis lineares ou subclavados

12. Lâminas foliares, especialmente as inferiores, fortemente atenuadas em direção à base, reduzindo-se praticamente à região da nervura central

13. Folhas glaucas. Entrenós da ráquis subclavados ou tendendo a lineares. Espiguetas sésseis com gluma inferior lanceolada A. glaucophyllus

13. Folhas verdes. Entrenós da ráquis filiformes a subclavados. Espiguetas sésseis com gluma inferior linear-lanceolada A. barretoi

12. Lâminas foliares de margens paralelas até a base, não atenuadas

14. Lâminas foliares cilíndricas, com a face adaxial reduzida a um pequeno sulco, rijas, menos freqüentemente planas na mesma planta. Gluma inferior da espigueta pedicelada 7-9-nervada

A. durifolius

14. Lâminas foliares planas, conduplicadas ou convolutas, não rijas. Gluma inferior da espigueta pedicelada 3-7-nervada 
15. Espiguetas pediceladas todas neutras, geralmente reduzidas ou rudimentares, raramente do mesmo comprimento das sésseis

16. Espiguetas sésseis com arista conspícua de 8-31 mm compr. Entrenós da ráquis e pedicelos com tricomas $1,5-2$ vezes o comprimento da espigueta séssil

17. Lígula membranoso-ciliada. Lâminas foliares 3,5-17 cm $\times 0,5-$ 2(-4) mm. Espiguetas pediceladas (2-)3,1-5 mm compr. Espatéola com 2-3(-5) ramos floríferos A. brasiliensis

17. Lígula membranoso-ciliolada. Lâminas foliares 4-38 cm $\times 2-7 \mathrm{~mm}$. Espiguetas pediceladas 0,2-4,5 mm compr. Espatéola com 2-11 ramos floríferos

18. Gluma inferior da espigueta séssil com 2-5 nervuras entre as carenas. Folhas glaucas

A. ingratus

18. Gluma inferior da espigueta séssil sem nervuras entre as carenas. Folhas verdes ou verde-vináceas

19. Lema inferior da espigueta séssil 3-nervado, com uma nervura central entre as carenas. Espiguetas pediceladas 3-5 mm compr. Entrenós da ráquis e pedicelos densamente pilosos. Espatéola com 2-3(-4) ramos floríferos A. ternatus

19. Lema inferior da espigueta séssil 2-nervado, sem nervura central entre as carenas. Espiguetas pediceladas 0,2-3 mm compr. Entrenós da ráquis e pedicelos com tricomas subdensos. Espatéola com (2-3)4-11 ramos floríferos

A. macrothrix

16. Espiguetas sésseis com arista inconspícua, de 0,5-6 mm compr., ou múticas. Entrenós da ráquis e pedicelos com tricomas 2-4 vezes o comprimento da espigueta séssil

20. Espiguetas pediceladas 3,3-6,3 mm compr., mais curtas ou mais longas que as espiguetas sésseis

A. arenarius

20. Espiguetas pediceladas 0,1-2(-3) mm compr., mais curtas que as espiguetas sésseis

21. Lâminas foliares 1-2(-3,5) mm larg., ápice agudo. Espiguetas sésseis 2,5-3,2(-3,8)mm compr. Tricomas dos entrenós da ráquis e pedicelos 3-4 vezes o comprimento da espigueta séssil....A. leucostachyus

21. Lâminas foliares (2,5-)-3-6(-10) mm larg., ápice obtuso-navicular. Espiguetas sésseis 3-5 mm compr. Tricomas dos entrenós da ráquis e pedicelos 2-3 vezes o comprimento da espigueta séssil

A. selloanus

15. Espiguetas pediceladas estaminadas, desenvolvidas, presentes em toda ou, ao menos, em parte da inflorescência, às vezes somente no ápice dos ramos floríferos, então as restantes neutras, menores ou do mesmo comprimento das sésseis

22. Inflorescências muito ramificadas, corimbiformes, congestas no ápice dos colmos floríferos. Espiguetas sésseis múticas

22. Inflorescências laxas, alongadas, terminais ou terminais e axilares, estas geralmente na metade superior dos colmos floríferos. Espiguetas sésseis múticas ou aristadas

23. Entrenós da ráquis e pedicelos com tricomas 2-3 vezes mais longos que o comprimento da espigueta séssil 
24. Espiguetas pediceladas geralmente estaminadas e neutras na mesma planta, as estaminadas (4-)6-7 mm compr. Calo da espigueta séssil com os tricomas mais longos alcançando (6-)8$14 \mathrm{~mm}$ compr. Arista da espigueta séssil 1-6 mm compr.

A. arenarius

24. Espiguetas pediceladas geralmente estaminadas, raramente neutras na mesma planta, as estaminadas 4,2-6,1 mm compr. Calo da espigueta séssil com os tricomas mais longos alcançando (2-)3-4(-6) mm compr. Arista da espigueta séssil 4-10,5 mm compr. A. lindmanii

23. Entrenós da ráquis e pedicelos com tricomas mais curtos ou até duas vezes o comprimento da espigueta séssil

25. Anteras das espiguetas sésseis e pediceladas subiguais no comprimento

26. Espiguetas pediceladas estaminadas e bissexuadas na mesma planta. Arista da espigueta séssil 4-7 mm compr. A. campestris

26. Espiguetas pediceladas todas estaminadas, ou estaminadas e neutras na mesma planta. Arista da espigueta séssil 8-24 mm compr. ou apenas vestigial no interior da espigueta 27. Espiguetas sésseis 4-5 mm compr., lema inferior 3-4 mm compr., pálea 1,9-3 mm compr. Folhas glaucas

A. ingratus

27. Espiguetas sésseis 5-7 mm compr., lema inferior 4-6 mm compr., pálea 0,8-1,1 mm compr. Folhas verdes

A. carinatus

25. Anteras das espiguetas sésseis e pediceladas desiguais no comprimento

28. Espiguetas pediceladas todas estaminadas, raramente algumas espiguetas neutras ocorrendo na mesma planta

29. Entrenós da ráquis e pedicelos glabros, ou com tricomas esparsos nas margens, tricomas mais curtos que a espigueta séssil

A. hypogynus

29. Entrenós da ráquis e pedicelos pilosos, tricomas distribuídos em toda a superfície abaxial ou especialmente no ápice e margens, tricomas mais curtos, subiguais ou alcançando até 1,3 vezes o comprimento da espigueta séssil

28. Espiguetas pediceladas estaminadas e neutras na mesma planta

30. Entrenós da ráquis e pedicelos com tricomas mais curtos que a espigueta séssil. Espiguetas sésseis geralmente múticas, às vezes múticas e aristadas na mesma planta

A. multiflorus

30. Entrenós da ráquis e pedicelos com tricomas 1,5-2 vezes o comprimento da espigueta séssil. Espiguetas sésseis sempre aristadas 
1. Andropogon angustatus (J. Presl) Steud., Syn. pl. glumac. 1:370. 1854.

Figura 1

Sul do México e Cuba até o Brasil: Ceará, Goiás, Maranhão, Mato Grosso, Paraíba, Rio Grande do Norte, Roraima.

Material selecionado: BRASIL. MARAnHÃo: São João dos Patos, 21-III-1985, J.F.M. Valls et al. 8454 (CEN, SP, UEC).

2. Andropogon arenarius Hack., Flora 68(8):134. 1885. Figura 2

Uruguai e Brasil: Paraná, Rio Grande do Sul, Santa Catarina, São Paulo.

Material selecionado: BRASIL. SANTA Catarina: Içara, Balneário Rincão, 22-XII-1998, A. Zanin \& A.C. Alves 755 (FLOR, SPF).

3. Andropogon barretoi Norrmann \& Quarín, Darwiniana 39(1-2):171-174. 2001.

Brasil: Rio Grande do Sul.

Material selecionado: BRASIL. Rio GRANDE Do SuL: 60 km E de Santa Maria, 9-III-1994, Norrmann, Keeler \& Barreto 146 (CTES, isótipo).

Norrmann \& Quarín (2001) descreveram A. barretoi, separando-a de A. glaucophyllus por caracteres que se sobrepõem, em sua maioria. Estes táxons são realmente de difícil separação e precisam ser melhor estudados, com outras abordagens além da macromorfologia.

4. Andropogon bicornis L., Sp. pl.:1046. 1753. Figura 3

México até a Argentina e Brasil: em todo o país, sem registro apenas para Rio Grande do Norte.

Material selecionado: BRASIL. Distrito FedERAL: Brasília, Reserva Ecológica do IBGE, 20-II-1997, A. Zanin \& H.M. Longhi-Wagner 486 (FLOR, SPF).

5. Andropogon brasiliensis A. Zanin \& LonghiWagner, Novon 13:368. 2003.

Figuras 4, 5

Brasil: Minas Gerais.

Material selecionado: BRASIL. MinAs GeRAIs: São Tomé das Letras, 6-XII-1997, A. Zanin \& H.M. LonghiWagner 673 (FLOR).

6. Andropogon campestris Trin., Mém. Acad. Imp. Sci. Saint-Pétersbourg, ser. 6, Sci. Math. Nat. 2(3):277. 1832. Figura 6
Brasil: Minas Gerais.

Material examinado: BRASIL. MinAs GERAIS: Serra da Lapa, s.d., Riedel 1134 (K, W).

7. Andropogon carinatus Nees, Agrostologia brasiliensis, in Mart., Fl. bras. enum. pl. 2(1):330. 1829.

Figura 7

Bolívia e Brasil: Distrito Federal, Goiás, Minas Gerais, Rio de Janeiro, São Paulo.

Material selecionado: BRASIL. Distrito FEDERAL: Brasília, Reserva Ecológica do IBGE, 15 56’ 41” S 47 53’07” W, 7-IX-1994, M.A. Silva 2448 (IBGE).

8. Andropogon crispifolius Guala \& Filg., Nordic. J. Bot. 15(1):59. 1995.

Figura 8

Brasil: Goiás, Mato Grosso, Mato Grosso do Sul.

Material selecionado: BRASIL. GoIÁs: Mineiros, about $10 \mathrm{~km}$ north of Parque Nacional das Emas, along the road to Mineiros, 15-V-1990, G.F. Guala \& T.S. Filgueiras 1345 (IBGE, parátipo).

9. Andropogon crucianus Renvoize, Gram. Bolívia:596. 1998.

Figuras 9, 10

Bolívia e Brasil: Bahia.

Material examinado: BRASIL. BAHIA: Ibicoara, 19

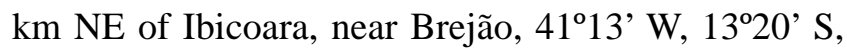
1-II-1974, R.M. Harley et al. 15771 (B, CEPEC, K, $\mathrm{MO})$.

10. Andropogon durifolius Renvoize, Kew Bull. 39(1):181. 1984.

Figura 11

Brasil: Bahia e Minas Gerais.

Material selecionado: BRASIL. BAHIA: Abaíra, Campo do Cigano, 24-II-1992, P.T. Sano \& T. Laessoe H52300 (SPF).

11. Andropogon fastigiatus Sw., Prodr. 26. 1788.

Figura 12

África. América Central até o Brasil: Bahia, Ceará, Distrito Federal, Goiás, Mato Grosso, Mato Grosso do Sul, Minas Gerais, Paraíba, Pernambuco, Piauí, Roraima, São Paulo, Tocantins.

Material selecionado: BRASIL. Mato Grosso DO Sul: Campo Grande, saída da cidade em direção a Aquidauana, 25-IV-1997, A. Zanin et al. 543 (FLOR, SPF). 
12. Andropogon gayanus Kunth, Enum. pl. 1:491. 1833. Figura 13

África. Introduzida no Brasil: em cultivo e margens de estradas, especialmente no Brasil Central.

Material selecionado: BRASIL. GoiÁs: Água Fria, estrada para São João da Aliança, 24-II-1997, A. Zanin \& H.M. Longhi-Wagner 511 (FLOR).

13. Andropogon glaucophyllus Roseng., B. R. Arrill. \& Izag., Gram. Urug. 165. 1970.

Figuras 14, 15

Uruguai e Brasil: Paraná, Rio Grande do Sul, Santa Catarina, São Paulo.

Material selecionado: BRASIL. RIo GRANDE Do SuL: Porto Alegre, Morro da Polícia, 3-XII-1999, A. Zanin \& H.M. Longhi-Wagner 763 (FLOR, SPF).

14. Andropogon glaziovii Hack. in Mart. \& Eichler, Fl. bras. 2(3):286. 1883.

Figuras 16, 17

Bolívia, Paraguai e Brasil: Goiás, Mato Grosso do Sul, Minas Gerais, São Paulo.

Material selecionado: BRASIL. SÃo PAULO: Guzolândia, SP 310, km 574, 12-VI-1999, A. Zanin 793 (FLOR, SPF).

15. Andropogon hypogynus Hack. in Mart. \& Eichler, Fl. bras. 2(3):290. 1883.

Figura 18

Bolívia, Paraguai, Argentina e Brasil: Mato Grosso, Mato Grosso do Sul, Minas Gerais.

Material selecionado: BRASIL. MATO Grosso DO Sul: Corumbá, estrada para o Porto da Manga, 19-VII-1998, A. Zanin \& T. Canto-Dorow 744 (FLOR, SPF).

16. Andropogon indetonsus Sohns, Mem. New York Bot. Gard. 9(3):269-271. 1957.

Figura 19

Brasil: Amazonas e Roraima.

Material examinado: BRASIL. AmAzonas. Encosta da Serra Aracá, 6-II-1978, N.A. Rosa \& S.B. Lira 2395 (MG).

17. Andropogon ingratus Hack., Oesterr. Bot. Z. 51(5):151. 1901.

Figura 20

Brasil: Minas Gerais, Bahia, Pernambuco.

Material selecionado: BRASIL. Minas Gerais: Santana do Riacho, estrada Conceição do Mato Dentro,
7-XII-1997, A. Zanin \& H.M. Longhi-Wagner 684 (FLOR, SPF).

18. Andropogon lateralis Nees, Agrostologia brasiliensis, in Mart., Fl. bras. enum. pl. 2(1):329. 1829. Figura 21

América do Sul. Brasil: Amazonas, Distrito Federal, Goiás, Maranhão, Mato Grosso, Mato Grosso do Sul, Minas Gerais, Paraná, Rio de Janeiro, Rio Grande do Sul, Santa Catarina, São Paulo.

Material selecionado: BRASIL. Rio GRANDE Do SuL: São Francisco de Paula, estrada para Tainhas, 22-XI-1996, A. Zanin \& H.M. Longhi-Wagner 322 (ICN).

19. Andropogon leucostachyus Kunth in Humb., Bonpl. \& Kunth, Nov. gen. sp. 1:187. 1816.

Figura 22

México até Argentina e Brasil: em todo o país, sem registro apenas para o Acre.

Material selecionado: BRASIL. PARANÁ: General Carneiro, saída BR 153 em direção a Bituruna, 24-I-1997, A. Zanin \& H.M. Longhi-Wagner 447 (FLOR, SPF).

20. Andropogon lindmanii Hack. in Lindm. Kongl. Svenska Vetenskapsakad. Handl. 346:6. 1900.

Figura 23

Uruguai e Brasil: Rio Grande do Sul e Santa Catarina.

Material selecionado: BRASIL. SANTA Catarina: Içara, Balneário Rincão, entre Lagoa dos Esteves e Lagoa Faxinal, 22-XII-1998, A. Zanin \& A.C. Alves 761 (FLOR).

21. Andropogon macrothrix Trin., Mém. Acad. Imp. Sci. Saint-Pétersbourg ser. 6 Sci. Math. Nat. 2:270. 1832.

Figuras 24, 25

Bolívia, Paraguai, Uruguai, Argentina e Brasil: Bahia, Distrito Federal, Espírito Santo, Goiás, Mato Grosso, Minas Gerais, Paraná, Rio de Janeiro, Rio Grande do Sul, Santa Catarina, São Paulo.

Material selecionado: BRASIL. SANTA CatARINA: Urubici, Morro da Igreja, 22-I-1997, A. Zanin et al. 422 (FLOR, SPF).

22. Andropogon monocladus A. Zanin \& LonghiWagner, Novon 13:370. 2003.

Figuras 26, 27

Brasil: Distrito Federal, Goiás, Bahia. 


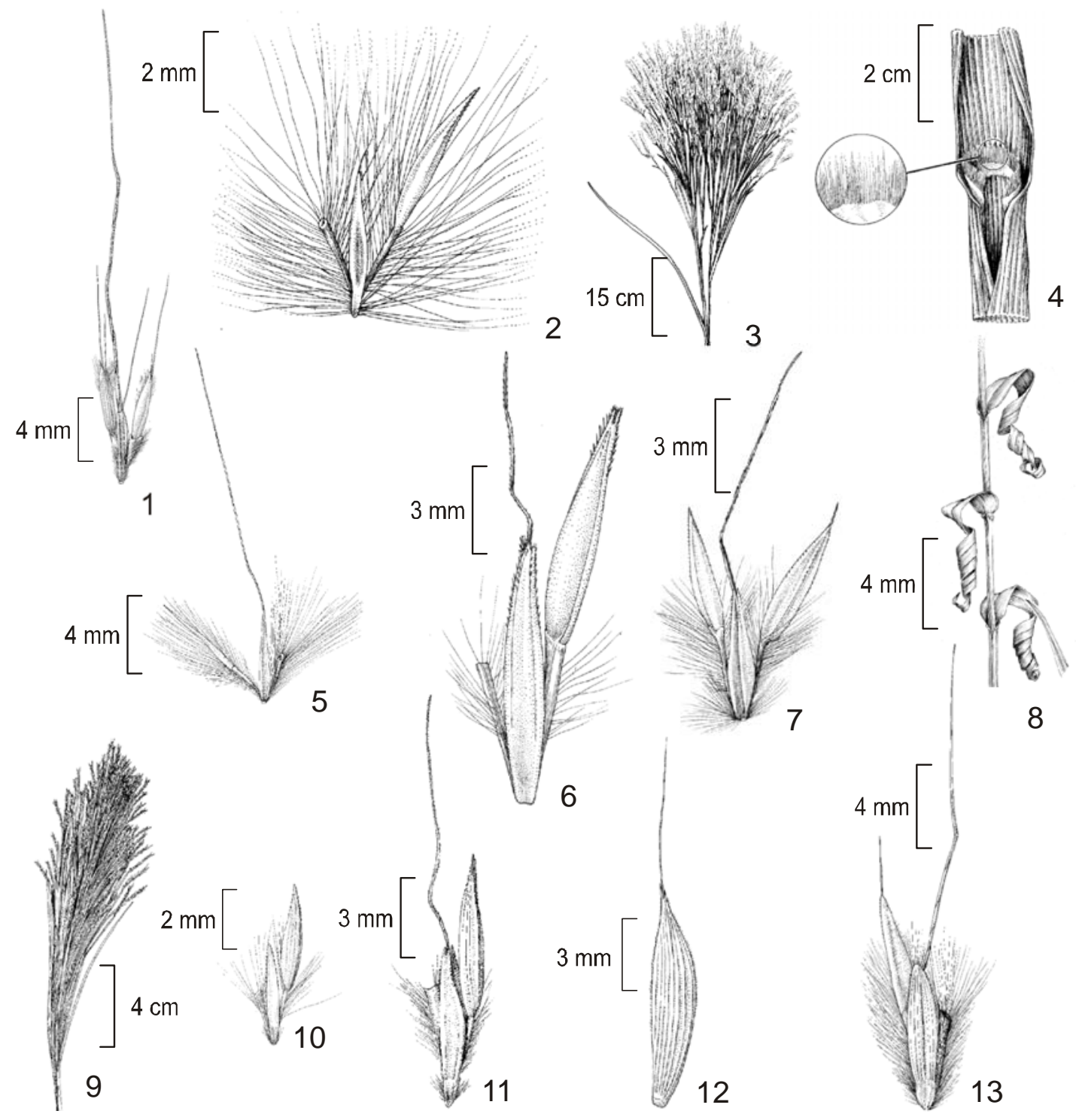

Figuras 1-13. Aspectos morfológicos de Andropogon. 1. Andropogon angustatus (J. Presl) Steud., diásporo do ápice do ramo florífero. 2. A. arenarius Hack., diásporo da porção mediana do ramo florífero. 3. A. bicornis L., inflorescência. 4-5. A. brasiliensis A. Zanin \& Longhi-Wagner. 4. Lígula membranoso-ciliada. 5. Diásporo da porção mediana do ramo florífero. 6. A. campestris Trin., diásporo da porção mediana do ramo florífero. 7. A. carinatus Nees, diásporo do ápice do ramo florífero. 8. A. crispifolius Guala \& Filg., lâminas foliares crispadas. 9-10. A. crucianus Renvoize, 9. Inflorescência. 10. Diásporo da porção mediana do ramo florífero. 11. A. durifolius Renvoize, diásporo da porção mediana do ramo florífero. 12. A. fastigiatus Sw., gluma inferior da espigueta pedicelada. 13. A. gayanus Kunth, diásporo da porção mediana do ramo florífero.

Figures 1-13. Morphological aspects of Andropogon. 1. Andropogon angustatus (J. Presl) Steud., terminal dispersal unit of the apex of a flowering branch. 2. A. arenarius Hack., dispersal unit of the midle portion of a flowering branch. 3. A. bicornis L.: inflorescence. 4-5. A. brasiliensis A. Zanin \& Longhi-Wagner. 4. Ligule membranous-ciliate. 5. Dispersal unit of the midle portion of a flowering branch. 6. A. campestris Trin., dispersal unit of the midle portion of a flowering branch. 7. A. carinatus Nees, dispersal unit of the apex of a flowering branch. 8. A. crispifolius Guala \& Filg., leaf blade crispate. 9-10. A. crucianus Renvoize. 9. Inflorescence. 10. Dispersal unit of the midle portion of a flowering branch. 11. A. durifolius Renvoize, dispersal unit of the midle portion of a flowering branch. 12. A. fastigiatus Sw.: lower glume of the pedicellate spikelet. 13. A. gayanus Kunth, dispersal unit of the midle portion of a flowering branch.

(1. J. F. M. Valls et al. 8525 (SP); 2. A. Zanin \& A.C. Alves 757 (FLOR); 3. A. Zanin 737 (FLOR); 4-5. A.B. Joly et al. 1851 (SP); 6. Riedel s. n. (W); 7. G.B. Black 548b (ESAL); 8. G.F. Guala \& T.S. Filgueiras 1345 (IBGE); 9-10. R.M. Harley et al. 15771 (MO); 11. G. Hatschbach 47997 (MBM); 12. A. Zanin et al.493 (FLOR); 13. A. Zanin et al. 583 (FLOR)). 

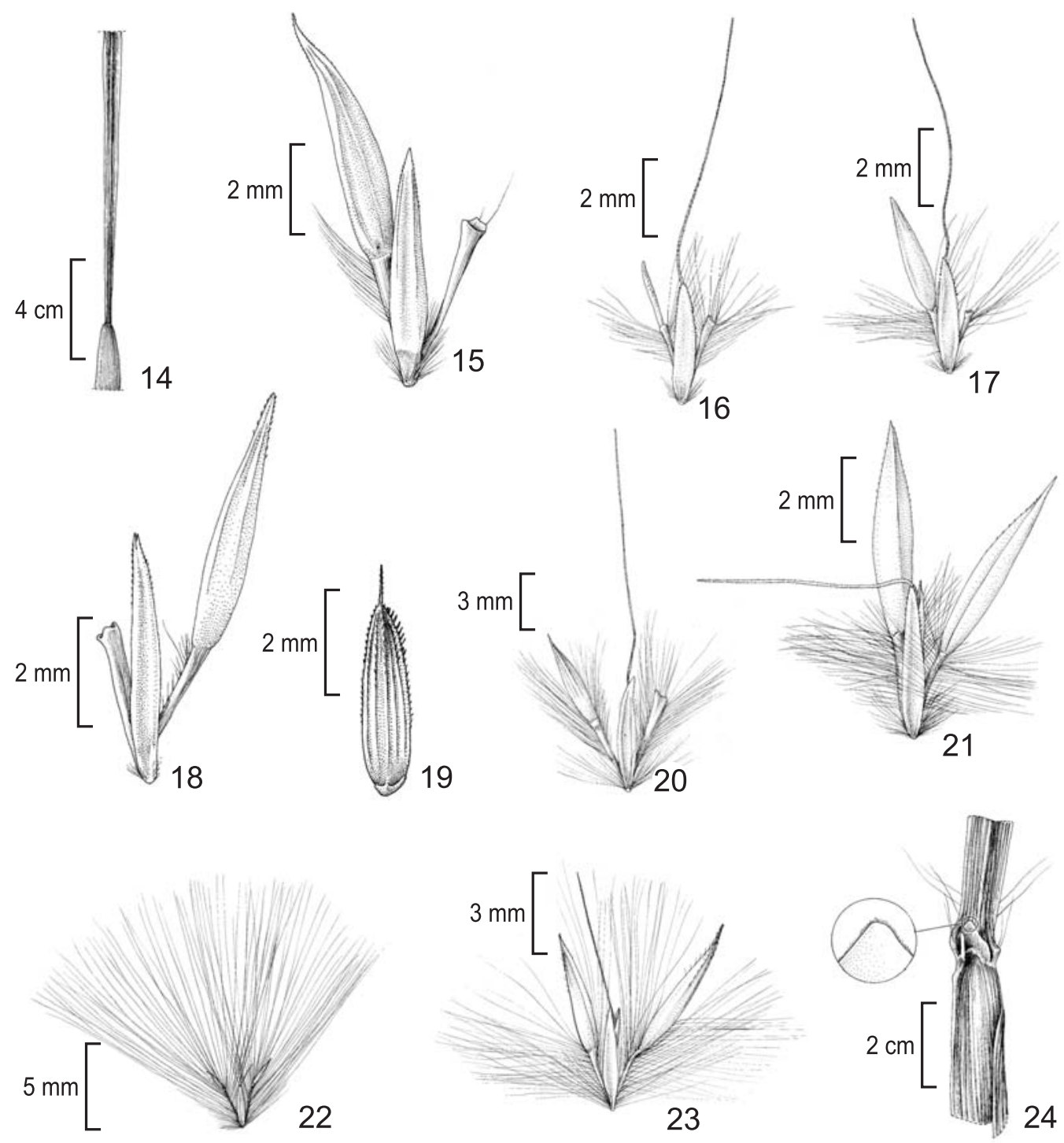

Figuras 14-24. Aspectos morfológicos de Andropogon. 14-15. Andropogon glaucophyllusose Roseng. 14. Base da lâmina foliar. 15. Diásporo da porção mediana do ramo florífero. 16-17. A. glaziovii Hack. 16. Diásporo da porção mediana do ramo florífero com espigueta pedicelada reduzida, neutra. 17. Diásporo da porção mediana do ramo florífero com espigueta pedicelada desenvolvida, estaminada. 18. A. hypogynus Hack., diásporo da porção mediana do ramo florífero. 19. A. indetonsus Sohns, espigueta pedicelada, pedicelo removido. 20. A. ingratus Hack., diásporo da porção mediana do ramo florífero. 21. A. lateralis Nees, diásporo do ápice do ramo florífero. 22. A. leucostachyus Kunth, diásporo do ápice do ramo florífero. 23. A. lindmanii Hack., diásporo do ápice do ramo florífero. 24. A. macrothrix Trin., lígula membranoso-ciliolada.

Figures 14-24. Morphological aspects of Andropogon. 14-15. Andropogon glaucophyllus Roseng. 14. Leaf-blade base. 15. Dispersal unit of the midle portion of a flowering branch. 16-17. A. glaziovii Hack. 16. Dispersal unit of the midle portion of a flowering branch, pedicellate spikelet rudimentary, neuter. 17. Dispersal unit of the midle portion of a flowering branch with a well developed pedicellate spikelet, staminate. 18. A. hypogynus Hack., dispersal unit of the midle portion of a flowering branch. 19. A. indetonsus Sohns, pedicellate spikelet, pedicel removed. 20. A. ingratus Hack., dispersal unit of the midle portion of a flowering branch. 21. A. lateralis Nees, dispersal unit of the apex of a flowering branch. 22. A. leucostachyus Kunth, dispersal unit of a flowering branch. 23. A. lindmanii Hack., dispersal unit of the apex of a flowering branch. 24. A. macrothrix Trin., ligule membranous-ciliolate.

(14. A. Zanin \& M. Zanin 770 (FLOR); 15. A. Zanin 541 (FLOR); 16-17. J.F.M. Valls et al. 11765 (CEN); 18. A. Zanin \& T. CantoDorow 744 (FLOR); 19. B. Maguire \& C.K. Maguire 40148 (IAN); 20. A. Zanin \& H.M. Longhi-Wagner 684 (FLOR); 21. I. Fernandes 451 (ICN); 22. A. Zanin \& H.M. Longhi-Wagner 469 (FLOR); 23. C.S. Campbell 4562 (SP); 24. A. Zanin \& H.M. Longhi-Wagner 435 (FLOR) ). 
Material selecionado: BRASIL. Distrito FEDERAL: Brasília, Cristo Redentor, 15-I-1991, P.S. Câmara \& T.S. Filgueiras 118 (IBGE).

23. Andropogon multiflorus Renvoize, Gram. Bolívia:596. 1998.

Figura 28

Bolívia, Colômbia e Brasil: Minas Gerais.

Material selecionado: BRASIL. MinAs Gerais: Diamantina, estrada Datas-Diamantina, BR 259, km 590, 10-XII-1997, A. Zanin \& A.C. Araújo 716 (FLOR, SPF).
24. Andropogon palustris Pilg., Bot. Jahrb. Syst. 30(1):137. 1901.

Figura 29

Brasil: Mato Grosso.

Material examinado: BRASIL. Mato Grosso: VII-1899, Pilger 732 (US).

25. Andropogon pohlianus Hack. in Mart. \& Eichler, Fl. bras. 2(3):304. 1883.

Figura 30

\section{Brasil: Goiás, Mato Grosso, Tocantins.}

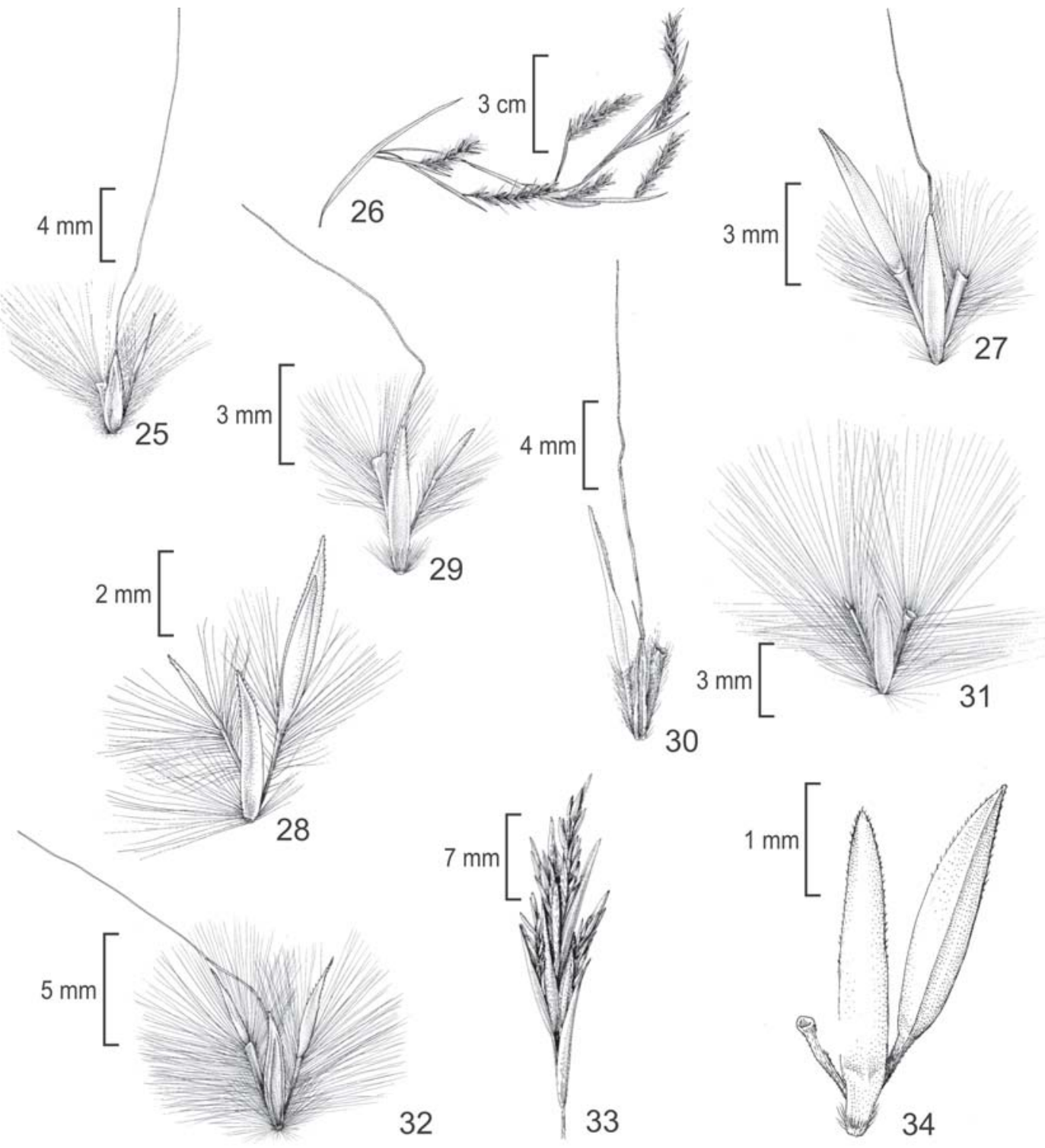

Figuras 25-34. Aspectos morfológicos de Andropogon. 25. A. macrothrix Trin., diásporo da porção mediana do ramo florífero. 26-27. A. monocladus A. Zanin \& Longhi-Wagner. 26. Inflorescência. 27. Diásporo da porção mediana do ramo florífero. 28. A. multiflorus Renvoize, diásporo do ápice do ramo florífero. 29. A. palustris Pilg., diásporo da porção mediana do ramo florífero. 30. A. pohlianus Hack., diásporo da porção mediana do ramo florífero. 31. Andropogon selloanus (Hack.) Hack., diásporo da porção mediana do ramo florífero. 32. A. ternatus (Spreng.) Nees, diásporo do ápice do ramo florífero. 33-34. A. virgatus Desv. 33. Inflorescência. 34. Diásporo da porção mediana do ramo florífero. 
Material selecionado: BRASIL. GoIÁs: Niquelândia, cerca $2 \mathrm{~km}$ da estrada para Macedo Velho, 14'21'13” S 48'24'52” W, 24-III-1995, F.C.A. Oliveira et al. 246 (SP).

26. Andropogon selloanus (Hack.) Hack., Bull. Herb. Boissier. 2(4):266. 1904.

Figura 31

México até a Argentina e Brasil: em todo o país, sem registro apenas para o Acre, Amapá e Rondônia.

Material selecionado: BRASIL. Minas Gerais: Jaboticatubas, acesso secundário à sede do Ibama, sede do Rio Cipó, 9-XII-1997, A. Zanin \& H.M. LonghiWagner 687 (FLOR, SPF).

27. Andropogon ternatus (Spreng.) Nees, Agrostologia brasiliensis, in Mart., Fl. bras. enum. pl. 2(1):326. 1829. Figura 32

Uruguai, Argentina e Brasil: Rio Grande do Sul e Santa Catarina.

Material selecionado: BRASIL. Rio GRANDE DO SUL: Bagé, 5 km do trevo em direção a Aceguá, 30-XI-1996, A. Zanin 344 (ICN).

28. Andropogon virgatus Desv. in W. Ham., Prodr. pl. Ind. occid.:9. 1825.

Figuras 33, 34

México até Argentina, Uruguai e Brasil: Amapá, Amazonas, Bahia, Distrito Federal, Maranhão, Mato Grosso, Mato Grosso do Sul, Minas Gerais, Pará, Paraná, Piauí, Rio Grande do Norte, Rio Grande do Sul, Santa Catarina, São Paulo, Tocantins.

Material selecionado: BRASIL. Mato Grosso: Chapada dos Guimarães, Parque Nacional da Chapada dos Guimarães, 27-XI-1997, A. Zanin et al. 667 (FLOR, SPF).

\section{Referências bibliográficas}

CLAYTON, W.D. \& RENVOIZE, S.A. 1982. Gramineae. In Flora of Tropical East Africa (R.M. Polhill, ed.). Balkema, Rotterdam, part 3, p.767-782.

CLAYTON, W.D. \& RENVOIZE, S.A. 1986. Genera graminum: grasses of the world. Her Magesty's Stationery Office. London, Kew Bulletin Additional Series, 13.

HACKEL, E. 1883. Gramineae - Andropogoneae. In Flora brasiliensis (C.F.P. Martius \& A.G. Eichler, eds.). F. Fleischer, Lipsiae, v.2, pars 3, p. 245-326.

HERVÉ, A.M.B. \& VALLS, J.F.M. 1980. O gênero Andropogon L. (Gramineae) no Rio Grande do Sul. Anuário Técnico do IPZFO 7:317-410.

NEES, C.G. 1829. Agrostologia brasiliensis. In Flora brasiliensis enumeratium plantarum (C.F.P. Martius, ed.). 2:320-331.

NORRMAN, A.G. \& QUARÍN, C.L. 2001. Andropogon barretoi, una nueva especie de Poaceae del sur de Brasil. Darwiniana 39:171-174.

RENVOIZE, S. 1984. The grasses of Bahia. Royal Botanic Gardens, Kew.

RENVOIZE, S. 1988. Hatchbach’s Paraná grasses. Royal Botanic Gardens, Kew.

SMITH, L., WASSHAUSEN, D. \& KLEIN, R. 1982. Gramíneas. In Flora Ilustrada Catarinense (R. Reitz, ed.). Herbário Barbosa Rodrigues, Itajaí.

STAPF, O. 1917-19. Gramineae. In Flora of Tropical Africa. (D. Prain, ed.). Reeve, London, p.1-265.

THE NEWYORK BOTANCAL GARDEN. Index Herbariorum. Disponível em http://sciweb.nybg.org/science2/ IndexHerbariorum.asp. (acesso em 11/02/2005).

ZANIN, A. 2001a. Revisão de Andropogon L. (Poaceae Panicoideae - Andropogoneae) no Brasil. Tese de doutorado, Universidade de São Paulo, São Paulo.

ZANIN, A. 2001b. Andropogon L. In Flora Fanerogâmica do Estado de São Paulo. v.1, Poaceae. (H.M. LonghiWagner, V. Bittrich, M.G.L. Wanderley \& G.J. Shepherd, eds.). Hucitec, São Paulo, p.91-96.

Figures 25-34. Morphological aspects of Andropogon. 25. A. macrothrix Trin., dispersal unit of the midle portion of a flowering branch. 26-27. A. monocladus A. Zanin \& Longhi-Wagner. 26. Inflorescence. 27. Dispersal unit of the midle portion of a flowering branch. 28. A. multiflorus Renvoize, dispersal unit of the apex of a flowering branch. 29. A. palustris Pilg., dispersal unit of the midle portion of a flowering branch. 30. A. pohlianus Hack., dispersal unit of the midle portion of a flowering branch. 31. Andropogon selloanus (Hack.) Hack., dispersal unit of the midle portion of a flowering branch. 32. A. ternatus (Spreng.) Nees, dispersal unit of the apex of a flowering branch. 33-34. A. virgatus Desv., 33. Inflorescence. 34. Dispersal unit of the midle portion of a flowering branch.

(25. A. Zanin \& H.M. Longhi-Wagner 435 (FLOR); 26-27. P.S. Câmara \& T.S. Filgueiras 118 (IBGE); 28. A. Zanin \& A.C. Araújo 719 (FLOR); 29. Pilger 732 (US); 30. F.C.A. Oliveira et al. 246 (SP); 31. A. Zanin et al. 407(FLOR); 32. A. Zanin et al. 387b (FLOR); 33. A. Zanin \& H.M. Longhi-Wagner 445 (FLOR); 34. A. Zanin et al. 608 (SPF) ). 